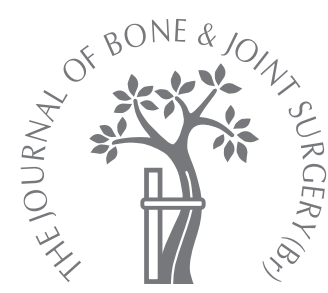

V. Bubbar,

F. Las Heras,

D. Amato,

K. P. H. Pritzker,

A. E. Gross

From Mount Sinai

Hospital, University

of Toronto, Toronto,

Canada

\title{
Total hip replacement in Gaucher's disease
}

\author{
EFFECTS OF ENZYME REPLACEMENT THERAPY
}

\begin{abstract}
Total hip replacement in patients with Gaucher's disease with symptomatic osteonecrosis of the femoral head is controversial because of the high early failure rates. We describe four patients who had an uncemented total hip replacement following enzyme replacement therapy for a median of two years and one month (1 to 9.8 years) prior to surgery, and who remained on treatment. At operation, the bone had a normal appearance and consistency. Histopathological examination showed that, compared with previous biopsies of untreated Gaucher's disease, the Gaucher cell infiltrate had decreased progressively with therapy, being replaced by normal adipose tissue. The surfaces of viable bone beyond the osteonecrotic areas showed osteoblasts, indicating remodelling. In one case acetabular revision was carried out after 11 years and eight months. The three remaining patients had a mean follow-up of six years and four months (3.3 to 12 years). We recommend initiating enzyme replacement therapy at least one to two years prior to total hip replacement to facilitate bone remodelling and to allow implantation of uncemented components in these young patients.
\end{abstract}

Gaucher's disease is the most common lysosomal storage disorder. ${ }^{1,2}$ There is an inherited deficiency of $\beta$-glucocerebrosidase, which is responsible for the breakdown of the lipid components of the cell membrane. As a result, lipid glucocerebroside is deposited in large quantities in the macrophage lysosomes in the spleen, liver and bone marrow, leading to hepatosplenomegaly, anaemia, thrombocytopenia and involvement of bone. ${ }^{1,3,4}$ Bone disease is characterised by a failure to remodel due to osteoclast dysfunction, osteopenia, the formation of lytic bone cysts due to failure of function of the osteoblasts, and osteonecrosis. ${ }^{5}$ Osteonecrosis of the femoral head is the most common symptomatic skeletal lesion. ${ }^{5-7}$ The acute phase of Gaucher's disease can result in long bone infarcts, known as bone crises, characterised by excruciating pain and disability. ${ }^{2,4,5}$ As a result, the bony manifestations in Gaucher's disease are a leading cause of pain and functional impairment. ${ }^{2}$

Approximately 20 years ago, enzyme replacement therapy to treat Gaucher's disease was discovered. Prior to this, the management of these patients was largely supportive. ${ }^{3}$ Enzyme replacement therapy has been shown to provide symptomatic improvement in pain, weight gain, reduction in bone crises and fatigue. Disease markers such as the size of the spleen and liver, blood counts, and the levels of acid phosphatase also improve after 12 to 20 weeks of treatment. Although improvement in the disease markers occurs early with enzyme replacement therapy, it is between 24 and 42 months before changes are seen radiologically. ${ }^{5}$ It is unclear whether destructive lesions are reversible. ${ }^{2}$

Total hip replacement (THR) for symptomatic osteonecrosis in Gaucher's disease is welldescribed. ${ }^{2,6-14}$ Most authors favour a cemented THR because of concerns about loosening with uncemented components owing to proliferation of Gaucher's cells at the bone-prosthesis interface. ${ }^{11}$ Despite cemented fixation, early failure rates are high, ranging between $13 \%$ and $56 \% .^{7-11,13,14}$ This has led some authors to recommend THR in young patients only as a last resort. ${ }^{6,7}$ We are not aware of any published series looking at uncemented THR in patients with Gaucher's disease following initiation of enzyme replacement therapy. We describe four patients who had been so treated for between one and nine years prior to an uncemented THR and who remain on treatment.

\section{Case reports}

We retrospectively reviewed the results of four patients with Gaucher's disease who had an uncemented THR for symptomatic osteonecrosis of the hip. All the operations were performed 
by the senior author (AEG) and the patients were managed and monitored by a haematologist with an interest in Gaucher's disease (DA). A single pathologist (KPHP) reviewed all the specimens and reported on the results.

Case 1 (enzyme replacement therapy for one year). The patient was diagnosed with Gaucher's disease at the age of nine years. She had a splenectomy at the same age and had multiple bony crises involving the left hip. She was treated with enzyme replacement therapy for one year prior to having a left THR at the age of 37 years for osteonecrosis. At the time of surgery, her body mass index (BMI) was $20 \mathrm{~kg} / \mathrm{m}^{2}$ and she was an ex-smoker, having quit one month before the operation.

In 1994 she had an uncemented THR through a direct lateral approach, with a trochanteric osteotomy. A proximal hydroxyapatite-coated titanium stem (Osteonics Omnifit HA, Stryker Orthopaedics, Mahwah, New Jersey), a $50 \mathrm{~mm}$ hydroxyapatite-coated acetabular shell with cluster holes (Stryker Orthopaedics), two acetabular screws and a standard polyethylene liner with a $10^{\circ}$ lip and a $28 \mathrm{~mm}$ head were implanted. The operative time was 2 hours and 20 minutes. An intra-operative crack of the calcar was treated with a cerclage wire. Pathological examination confirmed the diagnosis of Gaucher's disease with evidence of partial regression. She remained in hospital for eight days and received two units of blood after operation. She mobilised partially weight-bearing for six weeks and was anticoagulated with warfarin for three weeks.

At follow-up after 11 years and eight months she had no pain in the left hip, required no medication for pain, walked without aids and remained on enzyme replacement therapy. However, she had a fibrous union of the greater trochanteric osteotomy and radiological evidence of polyethylene wear and acetabular osteolysis. Therefore, in 2005, she underwent an acetabular revision.

The revision was carried out through a trochanteric slide approach. As expected, the polyethylene liner was worn and there was osteolysis. The acetabular shell was solidly fixed. Histological examination again revealed Gaucher's disease. The revision was accomplished with a $62 \mathrm{~mm}$ diameter porous tantalum revision acetabular shell (Zimmer Corporation, Warsaw, Indiana), two acetabular screws and a cemented, highly cross-linked polyethylene liner with a $20^{\circ}$ lip. There was a contained defect in the weight-bearing zone which was filled with morcellised allograft. The stem was solidly ingrown and only the femoral head was changed. The operative time was 2 hours 36 minutes, and she was transfused with one unit of blood. She was partially weight-bearing for six weeks, with no active abduction permitted for six months. Despite prophylactic anticoagulation with enoxaparin, she developed a pulmonary embolus post-operatively. She was therefore anticoagulated with warfarin for a total of six months. When followed up at four-months she had no pain and was mobilising well.

Case 2 (enzyme replacement therapy for $\mathbf{1 . 6}$ years). The patient was diagnosed with Gaucher's disease at the age of three

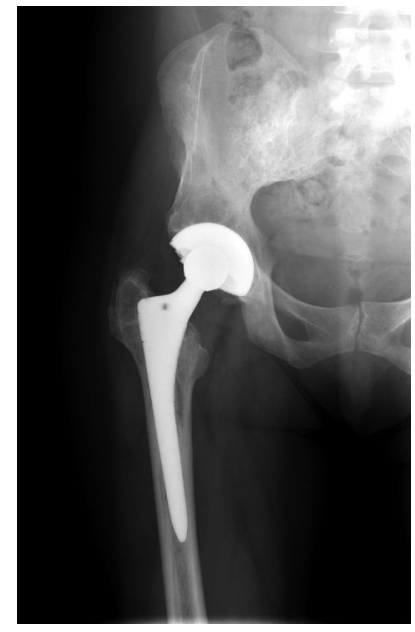

Fig. 1a

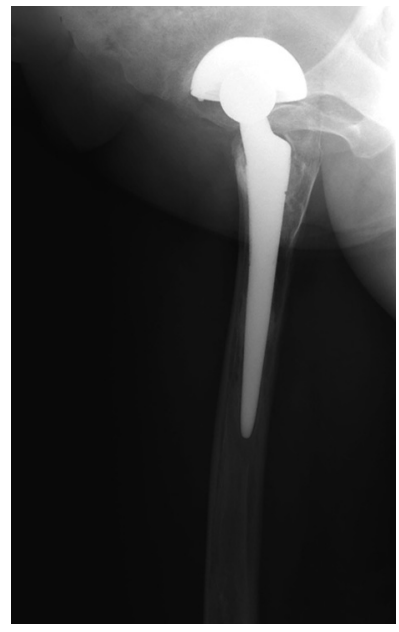

Fig. 1b
Case 2. a) anteroposterior and b) lateral radiographs of the hip eight years after uncemented total hip replacement.

years by bone marrow biopsy. She had a splenectomy at the same age because of rupture. A right innominate osteotomy with adductor tentomy was performed at the age of 12 years for hip pain and she suffered from multiple bony crises, including involvement of the right hip. She was treated with enzyme replacement therapy for one year and seven months prior to THR at the age of 34 years for osteonecrosis. At the time of surgery, her BMI was $24.8 \mathrm{~kg} / \mathrm{m}^{2}$ and she was a smoker.

In 1997 she underwent an uncemented right THR through a direct lateral approach. A titanium, tapered stem with circumferential proximal fibre metal surface and mid-stem corundumised surface (Zimmer Corporation), a $54 \mathrm{~mm}$ solid-backed acetabular shell (Zimmer Corporation), and a standard polyethylene liner with a $10^{\circ}$ lip and a $26 \mathrm{~mm}$ head were implanted (Fig. 1). The operation time was one hour 40 minutes, with no intraoperative complications. Histological examination confirmed the presence of Gaucher's disease. She remained in hospital for ten days. Post-operatively she was transfused with three units of blood, mobilised weight-bearing as tolerated, and was anticoagulated with warfarin for a total of four weeks.

When followed up after 11 years she had no pain in the right hip, required no medication for pain, walked without aids, and remained on enzyme replacement therapy.

Case $\mathbf{3}$ (enzyme replacement therapy for $\mathbf{2} \mathbf{6}$ years). The patient was diagnosed with Gaucher's disease at the age of 17 years by bone marrow biopsy. She had no history of bone crises but developed symptomatic osteonecrosis of the left hip (Fig. 2). She was treated with enzyme replacement therapy for two years and seven months prior to a left THR at the age of 46 years. At the time of surgery, her BMI was $21.8 \mathrm{~kg} / \mathrm{m}^{2}$ and she was a smoker. She had night pain and difficulties with activities of daily living. She was being 


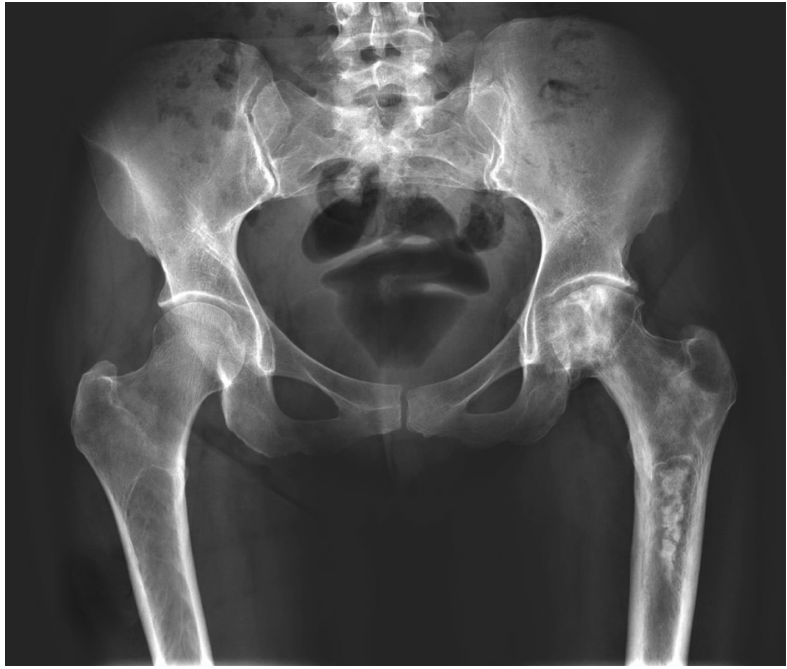

Fig. 2

Case 3. Pre-operative anteroposterior radiograph of the pelvis of a 46-year-old woman with symptomatic osteonecrosis of the left hip due to Gaucher's disease.

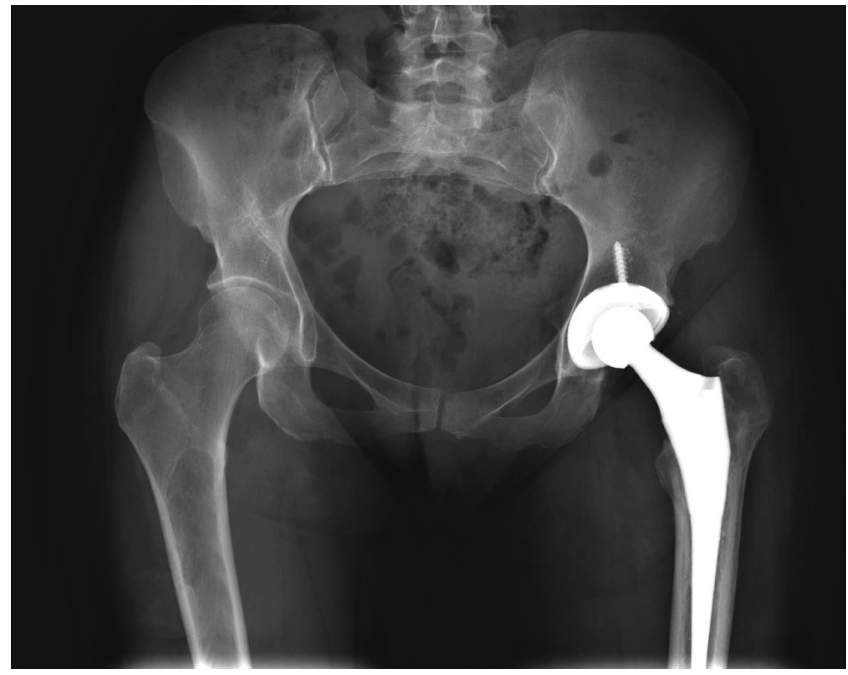

Fig. 3

Case 3. Post-operative radiograph two months after uncemented total hip replacement.

implanted. The operation time was two hours 43 minutes. Histological examination confirmed the presence of Gaucher's disease. Post-operatively she developed a haematoma which extended proximally into the retroperitoneum. This was treated conservatively, and she was transfused with five units of blood and six units of freshfrozen plasma. She remained in hospital, mobilised partially weight-bearing for six weeks, and was not anticoagulated because of the haematoma.

When seen after five years she had no pain in the left hip, required no medication for pain, walked without aids, and remained on enzyme replacement therapy.

\section{Results}

At operation, the typical greasy appearance of Gaucher's fatty infiltrate of the medullary canal, seen in untreated Gaucher's disease, was not seen. There was no clinical evidence of Gaucher's disease affecting the bone in any patient. The bone always had a normal gross appearance and material consistency. All patients had obvious osteonecrosis of the femoral head with deformation.

Histological examination of tissue removed at surgery identified Gaucher's disease and osteonecrosis in all four cases. Compared with Gaucher's disease before therapy, the cell infiltrate in our patients had decreased progressively (Fig. 4) and had been replaced by normal adipose tissue. Viable bone surfaces beyond the osteonecrotic areas showed osteoblasts, indicating that bone was remodelling

\section{Discussion}

Osteonecrosis of the femoral head is the most common skeletal lesion causing symptoms in patients with Gaucher's disease. Patients are typically young, and the morbidity is 


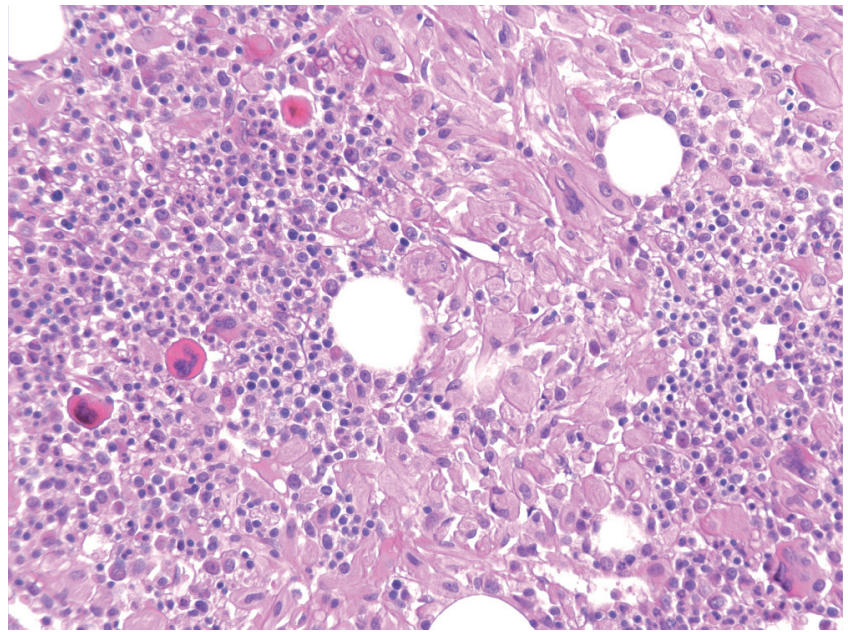

Fig. $4 a$

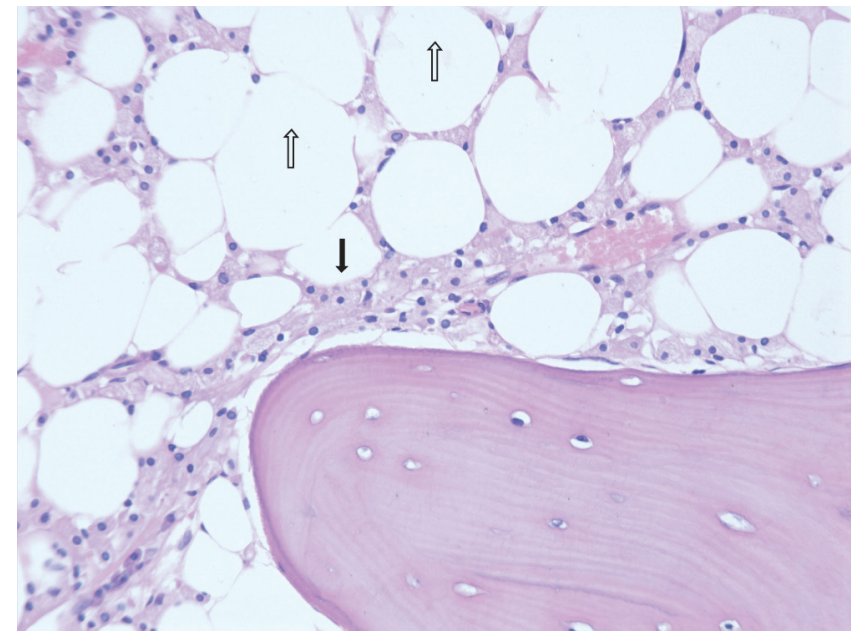

Fig. 4b

Case 4. Photomicrograph of histology showing a) Gaucher's disease bone marrow before enzyme replacement therapy (ERT), and b) Gaucher's disease bone marrow after nine years of ERT. Note the regression of Gaucher's cells (black arrow) and replacement of the marrow by fat cells (white arrow) (haematoxylin and eosin, original magnification $\times 250$ ).

significant..$^{5-7}$ Treatment has varied from cup arthroplasty to hemiarthroplasty to THR. ${ }^{6-14}$

Early studies from the 1980s identified concerns with THR in patients with Gaucher's disease because of high rates of aseptic prosthetic loosening, increased perioperative blood loss and a high rate of infection. ${ }^{8,9}$ This led many to reserve THR as a last resort for these patients. Lachiewicz et $\mathrm{al}^{9}$ followed seven cemented THRs in patients with Gaucher's disease for two to nine years. Three of the seven loosened. The authors noticed that loosening occurred in younger patients with more severe disease. They concluded that the rates of loosening were significant enough for THR to be considered with caution, and only after all other measures had failed. Lau et $\mathrm{al}^{8}$ described ten hips in six patients with Gaucher's disease treated with either cup arthroplasty or a cemented THR. The mean follow-up was five years and five months ( 4 years to 7 years 6 months). Of the seven THRs, three loosened. Four had developed a post-operative haematoma.

Goldblatt et $\mathrm{al}^{10}$ described 15 cemented THRs in eight patients with Gaucher's disease with a mean follow-up of 7.3 years (1 to 14 ), with excellent symptomatic and functional results. Of the 15 patients, two developed aspetic loosening, which was an improvement from earlier studies. $^{7-9}$ The authors advocated THR during a quiescent phase of symptomatic hip osteonecrosis.

Lebel et $\mathrm{al}^{7}$ published a series of 20 primary THRs in patients with Gaucher's disease: eight uncemented, eight cemented and four hybrid. The patients had a mean age of 43.8 years (17 to 65 ), and only three received enzyme replacement therapy prior to the THR. At a mean followup of 8.2 years, all the patients had a dramatic improvement in pain. The authors felt that THRs should be offered to patients with Gaucher's disease, using the same criteria as in other patients with osteonecrosis.
In 2002 George and Pearse ${ }^{6}$ described a cemented revision THR with impaction grafting for aseptic loosening of a primary cemented hip replacement in a patient with Gaucher's disease. The patient was treated with enzyme replacement therapy for one year prior to the revision procedure. At five years the patient had an excellent clinical result, with incorporation of the impaction bone graft.

Kumar and Rushton ${ }^{14}$ reviewed nine THRs in six patients with Gaucher's disease, seven with cemented procedures. Of these nine, five eventually required revision for loosening, but the mean time to revision was 11.4 years (6 to 19). This longevity more closely approximated to THRs performed for other indications. The authors concluded that THR can be successful in patients with Gaucher's disease.

In our small series, all four patients were on enzyme replacement therapy for a minimum of one year prior to THR and currently remain on this treatment. All had uncemented THRs with an excellent outcome. The intraand post-operative complications were not insignificant but pain relief and function were dramatically improved. At the time of THR, regression of the Gaucher's cell infiltrate in bone was observed, with very extensive improvement by nine years. The viable bone appeared normal. In all cases the uncemented components achieved excellent fixation. At follow-up, all patients showed radiological bone ingrowth of the uncemented prosthesis despite their Gaucher's disease and history of smoking.

The characteristic Erlenmeyer flask epiphyseal appearance of Gaucher's disease is related to failure to remodel. The osteonecrosis is related to the relative fragility of the unremodelled Gaucher bone. Both processes can be attributed to the effects of Gaucher's cells, limiting the functional capacity of the bone cells. The striking observation in this series is the regression of the Gaucher's cell infiltrate 
coupled with the renewed capacity to remodel bone, as observed by the presence of active osteoblasts and osteoclasts on the bony trabeculae. These observations are fully consistent with the macroscopic observations at operation when the bone appeared to have normal morphological and material properties.

Enzyme replacement therapy improved the quality of bone in these patients such that we were able to successfully implant an uncemented hip replacement. Histological examination demonstrated regression of the Gaucher cell infiltrate and the presence of osteoblasts and osteoclasts supports this hypothesis. Based on this experience, we recommend initiating enzyme replacement therapy at least one to two years prior to the THR to facilitate bone remodelling and allow implantation of an uncemented component in these patients. ${ }^{15-18}$

No benefits in any form have been received or will be received from a commercial party related directly or indirectly to the subject of this article.

\section{References}

1. Charrow J, Andersson HC, Kaplan P, et al. Enzyme replacement therapy and monitoring for children with type I Gaucher disease: consensus recommendations. J Pediatrics 2004;144:112-20.

2. Itzchaki M, Lebel E, Dweck A, et al. Orthopedic considerations in Gaucher disease since the advent of enzyme replacement therapy. Acta Orthop Scand 2004;75:641-53.

3. Mankin HJ, Rosenthal DI, Xavier R. Gaucher disease: new approaches to an ancient disease. J Bone Joint Surg [Am] 2001;83-A:748-62.
4. Lachiewicz P. Gaucher's disease. Orthop Clin North Am 1984;15:765-74.

5. Lebel E, Itzchaki M, Elstein D, et al. Skeletal manifestations in Gaucher's disease: presentation and treatment. Isr Med Assoc J 1999;1:267-71.

6. George MD, Pearse MF. Cemented revision total hip arthroplasty with impaction bone grafting in Gaucher's disease. J Arthroplasty 2002;17:667-9.

7. Lebel E, Itzchaki M, Hadas-Halpern I, Zimran J, Elstein D. Outcome of total hip arthroplasty in patients with Gaucher disease. J Arthroplasty 2001;16:7-12.

8. Lau MM, Lichtman DM, Hamati YI, Bierbaum BE. Hip arthroplasties in Gaucher's disease. J Bone Joint Surg [Am] 1981;63-A:591-601.

9. Lachiewicz PF, Lane JM, Wilson PD Jr. Total hip replacement in Gaucher's disease. J Bone Joint Surg [Am] 1981;63-A:602-8.

10. Goldblatt J, Sacks S, Dall D, Beighton P. Total hip arthroplasty in Gaucher's disease: long-term prognosis. Clin Orthop 1988;228:94-8.

11. Van Wellen PAJ, Haentjens $\mathbf{P}$, Frecoult $\mathbf{N}$, Opdecam P. Loosening of a noncemented porous-coated anatomic femoral component in Gaucher's disease: a case report and review of the literature. Acta Orthop Belg 1994;60:119-23.

12. Sellman DC, Froimson Al. Long-term follow-up of a total articular resurfacing arthroplasty and a cup arthroplasty in Gaucher's disease. Orthopaedic Review 1992;21:1099-101, 1104, 1107.

13. Laporte D, Mont M, Hungerford DS. Proximally porous-coated ingrowth prostheses: limits of use. Orthop 1999;22:1154-60.

14. Kumar V, Rushton N. Results of total hip arthroplasty in Gaucher's disease patients. Hip Int 2007;17:164-9.

15. Poll LW, Maas M, Terk MR, et al. Response of Gaucher bone disease to enzyme replacement therapy. Br J Radio/2002;74 (Suppl 1):25-36.

16. Rudzki Z, Okon K, Machaczka M, et al. Enzyme replacement therapy reduces Gaucher cells burden but may accelerate osteopenia in patients with type I disease: a histological study. Eur J Haematol 2003;70:273-81.

17. Wenstrup RJ, Kacena KA, Kaplan P, et al. Effect of enzyme replacement therapy with imiglucerase on BMD in type I Gaucher disease. J Bone Miner Res 2007;22:119-26.

18. Andersson H, Kaplan P, Kacena K, Yee J. Eight-year clinical outcomes of longterm enzyme replacement therapy for 884 children with Gaucher disease type I. Pediactrics 2008;122:1182-90. 